\title{
Spatial Location and Air Transport Connections: The Case of Minnesota's Medical Device Industry Cluster
}

\author{
Lee Munnich \\ Humphrey School of \\ Public Affairs \\ University of \\ Minnesota \\ lmunnich@umn.edu
}

\author{
Travis Fried \\ Humphrey School of \\ Public Affairs \\ University of \\ Minnesota \\ fried705@umn.edu
}

\author{
Joanne Cho \\ Humphrey School of \\ Public Affairs \\ University of \\ Minnesota \\ choxx589@umn.edu
}

\author{
Thomas Horan \\ School of Business \\ University of Redlands \\ Thomas_Horan@redlands.edu
}

\begin{abstract}
Minnesota's medical device industry cluster is not only one of the biggest driving economic forces in the state, but also a global leader in the development and distribution of medical devices. The study assessed the medical device industry's spatial development and air transport implications, both in terms of industry cluster location and flow of products. The spatial analysis showed that most medical device companies are located within the seven-county Twin-Cities region, but that industries linked to the medical device industry cluster are much more dispersed throughout the state. Regarding products created, the supply chain of medical devices is highly dependent on Minneapolis-St Paul Airport (MSP), which plays a key role in their delivery of medical devices. Air Cargo analysis reveals the high value of medical devices. exports to various locations and raises issues about the future role of air cargo through MSP to the economic prosperity of the industry cluster.
\end{abstract}

\section{Introduction}

Minnesota enjoys a vibrant economy due to the success of numerous companies that are household names-3M, Target, Best Buy, Medtronic, Mayo Clinic. According to Minnesota Department of Employment and Economic Development (DEED), in 2018, Minnesota's exports were estimated at a value of $\$ 22.7$ billion -ranking 20th in the nation. Compared to 2017 , it was a 10 percent increase, setting a state record high in exports. In addition, the 10 percent increase in export value in 2018 compared to 2017 was 2 percent higher than the national average of 8 percent.
The medical device industry is a key contributor to the state's economic success. In fact, Minnesota has one of the strongest medical device industry clusters in the country. Out of the $\$ 22.7$ billion in annual exports in 2018, the medical device and pharmaceutical industry represented the single largest export in terms of value accounting approximately 23 percent of Minnesota's total export value. The medical device industry in Minnesota also saw an increase in exports compared to 2017, with business relationships expanding beyond state-borders to major global markets in Europe and Asia [1].

This growth has propelled Minnesota to be the top state in the nation in terms of the highest concentration of medical device companies and the second highest in terms of medical device employment [ 1 ]. It is without a doubt that Minnesota's reputation as home to many wellestablished healthcare facilities plays an integral role in making Minnesota the headquarters for medical device companies. Moreover, observations by key actors in the medical device industry suggest there is plenty of room for further growth [2]. This study aims to uncover spatial and transportation dynamics associated with this growth.

\section{Literature Review}

\subsection{Industry Cluster Model of Competitiveness}

A landmark work on the role of industry clusters was Michael Porter's The Competitive Advantage of Nations [3]. In this work and related publications, Porter outlined the critical role of industry clusters as 
engines of regional prosperity, especially those "traded" clusters that reach a global market [4]. Porter has applied this model to explain the growth of various industry clusters in the US (and globally), including the rise of the medical device cluster in Minnesota [5].

Beyond Porter, industry cluster studies have become a staple of economic development analysis as well as further academic analysis [6]. Industry clusters succeed through interdependency where the immersion of skills and knowledge from different economic sectors helps improve productivity [7]. Ketels and Memdovic note that there are three critical components that play a role in defining clusters: geography, value creation, and business environment [8]. In addition, clusters are also created based on the accessibility of skilled labor force, space, suppliers, and infrastructure [9].

In terms of the geography of industry clusters, while clusters can occur in metropolitan or rural areas, the dominant focus has been on major clusters (e.g., technology, health) located in metropolitan areas. This is understandable as the majority of the country's production occurs in and around metropolitan areas. That said, there are noteworthy examples of clusters that have developed across rural regions, including several in "Greater" (small cities and rural) Minnesota [10].

However, despite the use of clusters as an indication of economic activity and growth, the presence of industry clusters does not guarantee future economic growth. Geographic regions that seek to benefit from the persistence of industry clusters in the area must ensure collaboration between businesses and the public sector so as to maintain a business environment that allows and encourages competition [11].

\subsection{Air Transportation and Industry Clusters}

Airports have long been heralded as a vital element for economic growth and competitiveness. John Kasarda purports that, much like the seaports and union railway stations of the $19^{\text {th }}$ and $20^{\text {th }}$ century, contemporary airports link communities to the global marketplace and drive urban development beyond the airfield fence [12]. Kasarda suggests that major airports act as focal points for business development and firm location decisions. While resources exist for managing airport cargo operations - see ACRP Report
143 [13] - there is a dearth of research in comparison to passenger travel, which is considered the principal revenue stream for major airports and airlines.

This state of research is surprising given air cargo's physical and economic prominence. Nearly every commercial airport handles some combination of dedicated freighter aircraft (i.e., independent carriers contracted by ground-based freight forwarders), integrators (i.e., integrated ground-toair forwarding services), and/or passenger planes with cargo stored in the belly (i.e., 'combination carriers'). Some airports (e.g., MEM, Memphis, a FedEx hub, and SDF, Louisville, a UPS hub, respectively) have highly specialized in air cargo operations [14].

Air cargo operations allow local industry clusters to access the global, high-value economy that drives regional economic competitiveness. In fact, despite handling only 3 percent of the total volume, airports move more than $33 \%$ percent of the value of globally traded merchandise [15]. Kupfer et. al. explain that as this value increases - and in fact, Boeing anticipates this value to grow 4 percent per year in the upcoming decade [16] — so too does the demand for air cargo [17]. This trend is especially impactful for growing, high-tech and service-based economies [18].

A handful of recent studies link air cargo service to enhanced regional development [19]. The majority focus on the causal relationship between metropolitan economies and cargo traffic at large airport hubs. Lakew uses linear regression to underline how growing wages and employment shares in high-value service jobs - such as tech and healthcare-lead to increased, especially domestic, demand for air cargo [20], [21]. Button and Yuan further argue that cargo airports stimulate regional economic development through immediate employment and long-term industry benefits [22]. Non-hub (or 'spoke') airports also play a crucial role in smaller, regional economies. For instance, in the Baltic States - a peripheral region in the European economy-researchers note how cargo airports adapt to local industry demands, improve regional market attractiveness, and promote entrepreneurial innovation [23].

\section{Minnesota Medical Device Industry Cluster}




\subsection{Minnesota Medical Device Industry}

Minnesota's Medical Device Industry Cluster can be traced back to the founding of Medtronic by Earl Bakken in 1949. In the subsequent seven decades Minnesota has become the leading state in the nation in terms of medical industry cluster concentration. With a nation-leading location quotient (LQ) of 4.06, it has four times the national average of medical device industries, and is home to Medtronic, Boston Scientific, Abbott Labs, 3M and major healthcare centers like the Mayo Clinic It also has the nation's second highest employment for medical device manufacturing [24].

With a thriving medical device industry in Minnesota, other complementary economic sectors providing goods and services also have the opportunity to evolve as specialized industries. There are nine related industry clusters that have been identified as linked to the medical device industry cluster in Minnesota. The nine linked clusters are: biopharmaceutical, distribution \& e-commerce, jewelry, recreational goods, electrical wiring, plastics, IT, production technology, and downstream metals [25]. Considering the possible economic development opportunities and implications in "Greater" Minnesota, transportation infrastructure and logistics enterprises need to be well positioned to retain Minnesota's competitive advantage and economic development throughout the state.

\subsection{Minnesota Transportation Context}

The medical device industry cluster relies heavily on a combination of surface and air transportation. Therefore, to satisfy their consumers who are located nationally and globally and provide reliable, fast and cost-efficient deliveries it is crucial to have a welldesigned multimodal transportation system that supports not just the end delivery of medical devices but the medical device industry's supply chain. The Minnesota Department of Transportation (MnDOT) recognizes the role of transportation when it comes to this economic growth. Without an efficient transportation system that facilitates the movements of goods, the state's economy can be jeopardized. As a result, MnDOT has made direct and indirect investments related to the state's transportation network to maximize its economic potential. Most recently, the state has established a $\$ 1$ billion
"Corridors of Commerce" investment program that focuses on improvements in moving commerce throughout the state [26].

With regard to trading medical device products, the Minneapolis-St. Paul International Airport (MSP) plays a crucial role and these goods represent some of the highest value shipments out of MSP. However, policy surrounding MSP has generally been passenger-oriented, but there is a growing recognition that air-freight deserves additional attention. One recent motivator for this attention is the medical device supply chain challenges confronting Minnesota industries that are manufacturing COVID-19 related medical equipment [27]. More generally, a common concern has been the lack of detailed data to inform decisions on air cargo policy. While advances have been made in terms of robust air passenger data, efforts to devise supply chain oriented data are just getting underway.

The common benchmark used to measure freight movements - ground, air, or maritime - has been volume rather than the value of the goods. From a logistics perspective a volume focus makes sense, as volume dictates floor space on cargo bays, handling operations, and surface and air traffic. However, it is incorrect to conclude that a simple increase in the volume of cargo over time would translate to an increase in economic gains, especially considering medical commodities are generally low volume but high value. There is a need to look closely at the its changing value of the goods based on price per weight and its affect on the total state Gross Domestic Product (GDP). For example, in Minnesota, the volume of all goods traded via air increased roughly 11 percent between 2012 and 2015. Yet, as will be elaborated below, the value of medical goods being transported via air increased by almost 40 percent in the same timeframe.

\section{Methodology}

\subsection{Research Objectives}

The above discussion highlights the importance of the medical device industry cluster. Despite the interconnectedness of the medical industry cluster and transportation, little has been done to spatially and quantitatively analyze this relationship between transportation and industry cluster competitiveness, 
especially as these industries adapt and evolve to growing demand.

This research study is aimed to further understand the impact that the medical device industry cluster has on economic development and competitiveness and to identify transportation related issues that affect growth and industry development. The study objectives are two-fold: 1) to analyze the Minnesota medical device industry cluster in terms of its spatial growth and 2) to analyze the air transport implications for the trade flows of these industry products.

\subsection{Spatial Analysis of Cluster Locations}

There are several different ways to analyze industry clusters, whether the interest is competitiveness, economic performance, location quotient of an industry, or spatial growth. For the purpose of this study, the interest is spatial growth and therefore we conduct spatial analysis. The main tool utilized to perform a spatial analysis was ArcGIS, utilizing business data obtained by ReferenceUSA [28]. As part of this analysis, companies were selected based on Medical Device Industry Cluster categorization outlined in EDA's U.S. Cluster Mapping Tool developed by Harvard Business School.

ReferenceUSA is a database that provides business and consumer information. Providing detailed information about companies, ReferenceUSA users are able to filter their searches based on different categories such as location of company, size, NAICS code, zip code, year of establishment, etc. Due to the search engine's versatility as well as Reference USA being one of the very few robust databases available, ReferenceUSA is often utilized by MPOs and other regional, local, and state agencies to obtain business and consumer information.

Spatial analysis takes the employment data and performs hotspot analysis based on the distance between points and their neighboring features. In ArcGIS, the Kernel Density geoprocessing tool helps calculate the density of points in a given area and creates a hotspot based on each point's approximation from one another. The Kernel Density tool is often implemented to map population, crime rate, congestion, etc. There are other helpful ArcGIS tools that can be implemented, such as, the Space Time Cube. However, it was not the appropriate tool to be used as the data pool was too small and insufficient.

\subsection{Industry Cluster Data Sources}

The 2012 US Cluster Definition provides an industry code for each industry and the relevant NAICS codes that fall under that specific industry. Having identified the nine industry clusters linked to the medical device industry through the Cluster Mapping Tool, the US Cluster Definition list was used as a reference to extract a list of all the relevant NAICS codes based on the nine linked industry clusters' cluster codes [29]. Once a list of NAICS codes was developed, NAICS codes that were considered irrelevant to the medical device industry were excluded from the list. For example, the NAICS code "33112" falls under the "Production Technology" linked industry cluster. However, NAICS code 33112 descriptions is: "Lawn and Garden Tractor and Home Lawn and Garden Equipment Manufacturing." The exclusion of certain NAICS code to the final list was based on the NAICS code descriptions and their relevance to the medical device industry.

Based on the compiled list of NAICS code, we extract businesses and companies with matching NAICS codes from ReferenceUSA. A total of 6,291 businesses and companies were identified as part of the nine linked industry clusters in Minnesota while 493 medical device companies were located within the state.

\subsection{Air Transport Data Sources}

This study also utilized GIS-based approach to analyze the complex linkages between Minnesota airports within the medical commodity supply chain, fusing two highly comprehensive freight datasets in the process-FHWA's Freight Analysis Framework 4 (FAF4) and the Bureau of Transportation's (BTS) T100 air carrier statistics form.

BTS T100 reports monthly volumes of passenger, freight, and mail between all domestic and international airports terminating or originating in the U.S. between 1990 and 2017. This study operationalizes cargo as the sum of freight and mail; since 2004, integrators have reported shipment volumes as either freight or mail.

Medical commodity value data was obtained from the FAF4 CFS dataset, which records 
commodity O-D movement by various modes on the state or FAF zone geographic level. The Standard Classification of Transported Goods (STGC2) identifies commodity type. The study classifies medical commodities as the combination of precision instruments and pharmaceuticals. Note that precision instruments include imaging and measuring apparatuses for medical and other purposes. This study pulls medical commodity value flow data between all states and Minnesota FAF zones (Greater MN and Twin Cities metro area) by air between 2012 and 2015. Air mode denotes all truck-to-air movements over 100 lbs.

\subsection{Spatial Analysis of Air Transport}

This analysis integrates a variety of spatial datasets to approximate medical freight-value distribution between origin-destination (O-D) airports given total air cargo volumes and state-level commodity data. (See Figure 1). The model begins by building a PostgreSQL database to fuse the BTS T100 and FAF4 datasets. PostgreSQL is an open-source, object-relational database management system capable of efficiently querying big, spatially indexed datasets using the PostGIS extension. The analysis model includes all domestic airports with regularly scheduled cargo movements that either terminate at or originate from Minnesota airports.

The model disaggregates freight-value O-D movement from a state- to airport facility-level using a series of weights. Weights purport shippers transport the highest value of medical commodities to airports that handle high cargo volume and exhibit large numbers of medical establishments within their market catchment area. Alkaabi and Debbage determined the relationship between medical establishment counts and air cargo volume [30]. The database includes two additional datasets that use establishment counts as weights: the FDA medical device and pharmaceutical registration list and U.S. hospital locations

The model also considered the effect that large airports have on smaller, adjacent airports. Studies suggest that airports shipping over 1530 thousand tons of cargo per year exert a 'traffic shadow' effect. For many shippers, distant large hub airports prove more attractive than closer regional airports[31]. This phenomenon is often referred to as 'cargo leakage.' For instance, 80 percent of all Minnesota-generated cargo leaks (i.e., trucks) to Chicago O'Hare (ORD), a substantially larger airport hub.[32]

In the model, the traffic shadow effect assumes which airport serves as the most attractive market option for each medical freight generator and receiver. An approximated catchment area (roughly 90 miles) is utilized to tabulate the count variables. The study determines the uniform catchment area based on interviews with airport logistics operators. The traffic shadow effect assumes that when deals with cases in which two or more airport catchment areas overlap cargo will be assigned to the larger airport, despite relative distance between the freight generator/receiver and the airports.

Figure 1 illustrates the database entity relationships used to calculate and assign freightvalue, where weights - represented by the site counts in the 'Generator' and 'Receiver' index tables - are calibrated at the state-level (OD state).

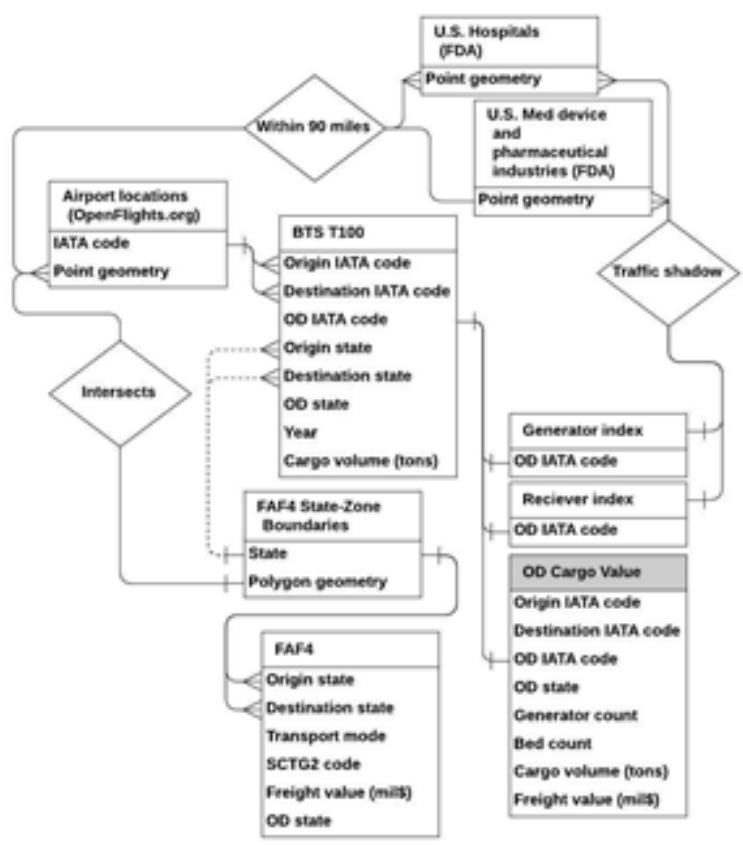

Figure 1: Medical Device Air Transport Model 


\section{Results}

\subsection{Medical Device Spatial Distribution}

Based on spatial analysis of ReferenceUSA data, there were only 21 medical device companies recorded in 1983. Currently, 37 years later, there are 234 medical device companies. While most of the medical device companies' headquarters and facilities are concentrated within the Minneapolis-St. Paul sevencounty region -which includes Hennepin, Ramsey, Carver, Scott, Washington, Anoka, and Dakota County - the medical device industry's success has benefited those outside of the Minneapolis-St. Paul metro region. Suppliers who provide parts to medical device companies are often located outside of the seven-county region. And as these suppliers rely on doing business with medical device companies, the success of the medical device industry in Minnesota ultimately fosters the growth of other industries that are located throughout the state.

Figures 2 and 3 summarize these spatial analysis results. The map first displays the density of medical device companies within one square mile of one another. It is clear that there is a higher concentration of medical device companies located within the metro area. However, the second map shows the location of businesses that are identified as one of the nine industry clusters linked to the medical device industry cluster: distribution \& e-commerce, jewelry, recreational and small electric goods, lighting and electrical equipment, plastics, information technology, production technology, and downstream metals. These linked cluster companies are much more dispersed throughout the state.

In short, the spatial analysis reveals the medical device industry in Minnesota is not only experienced by those in the Twin Cities metropolitan region but also by those in "Greater" Minnesota. While medical device companies were highly concentrated in the Minneapolis-St. Paul seven-county region, companies identified as one of the nine linked industry clusters were more dispersed in the 80 counties of Greater Minnesota. With some even located closer to the state's northern limits, the resulting map highlights why transportation is an integral part of economic growth and development of the medical device industry cluster.

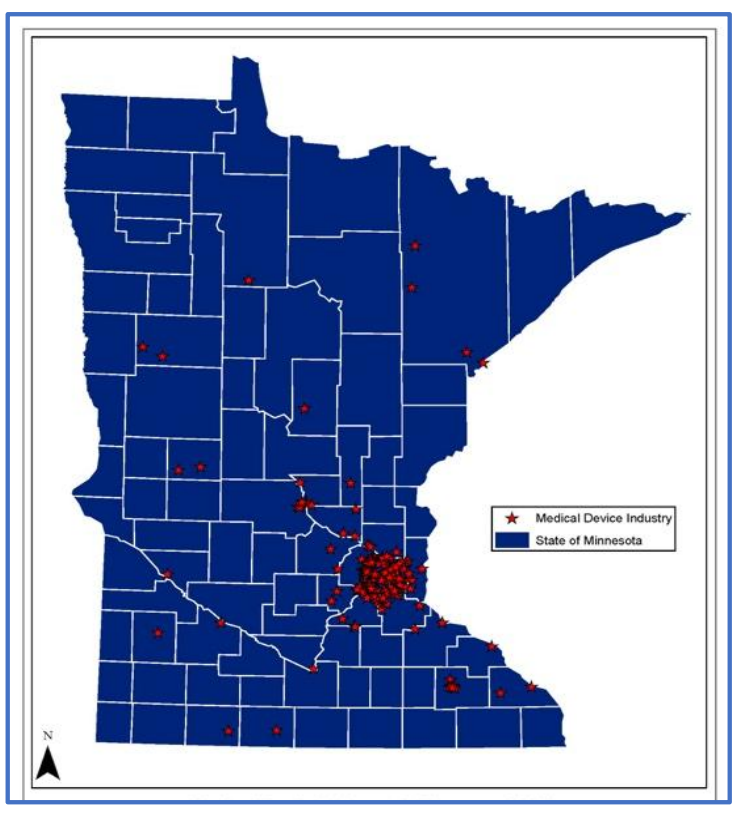

Figure 2. Medical Device Companies

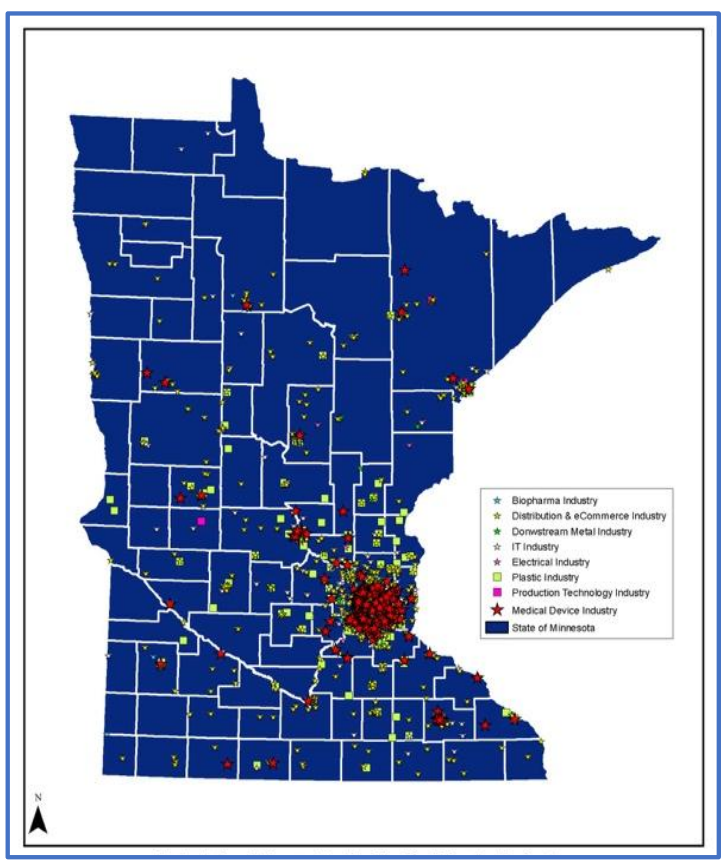

Figure 3. Medical Device and Linked Industries 
Given this broad spatial organization of medical device and linked industries, it is important to have a well-planned transportation network that enables a punctual production timeline. Production of medical device goods can and will be delayed if parts do not arrive on time to manufacture the final goods. One way to minimize transportation related issues in the supply chain logistics is to minimize the delivery distance. However, not all companies are able to relocate closer to their clientele due to limited space availability, restricted land use, high rent, labor costs, limited access to skilled labor pool, etc. Micco and Serebrisky's research note that transportation costs can be minimized in areas where airport access is easier and the air cargo market is liberalized [33].

In short, this analysis shows the connectivity between the Twin Cities metropolitan region and Greater Minnesota. While major headquarters and main manufacturing firms may be located closer to the Twin Cities metropolitan region, businesses that manufacture and provide parts and raw materials for the final product are spatially dispersed throughout the state. The medical device industry's success in Minnesota has been possible due to the complementary relationship between businesses in Greater Minnesota and the Twin Cities metropolitan region. Without the support of one another, facilitated by efficient and reliable transportation, the medical device industry would not have been so prolific, and this synergistic relationship is important if the medical industry cluster is going to continue to grow as a vital part of Minnesota's economy. The next section analyzes the import and export of medical device cargo from and to Minnesota.

\subsection{Minnesota's Medical Airfreight Network}

Minnesota has six regularly scheduling airports domestically importing and exporting roughly 111 and 119 thousand tons of medical commodities in 2015. Figure 4 shows how the volume of Minnesota airtraded goods increased substantially between 2012 and 2015, from about 207 to 230 thousand tons (a roughly 11 percent increase). However, the value of air-traded medical goods had a sharper increase in the same timeframe from $\$ 6.8$ to $\$ 9.4$ billion (a roughly 38percent increase). Moreover, the data show that even though Minneapolis-St. Paul (MSP) airport handles the lionshare of air trade (94 percent of all domestic import and export volume), Rochester (RST) airport, which serves the Mayo Clinic, handles roughly 8percent of air-traded medical value. In fact, the air linkage between Rochester and Memphis is the fourth highest in medical domestic export value in the state.

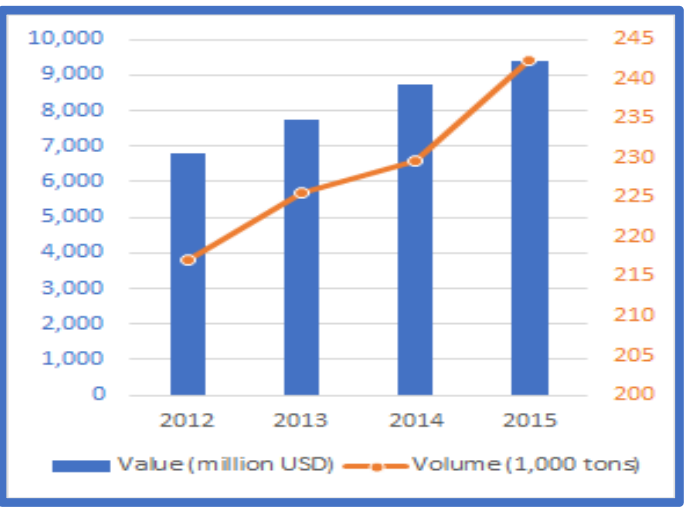

Figure 4: Air cargo volume and value of air-traded medical goods to and from MN airports, 2012-2015

Thus, MSP is the state's primary cargo portal for medical devices. FedEx is the primary air shipper of Minnesota goods, carrying roughly 46 percent of all goods to and from Minnesota airports. However, there is a diverse array of air cargo carriers operating at MSP. Roughly, 20 percent of cargo volume is carried by a combination carrier-primarily, Delta and Sun Country (a regional carrier). Meanwhile, 10 percent of cargo volume is moved by dedicated, nonintegrator aircraft. These carriers are primarily responsible for international movements on widebodied aircraft while integrators transport the vast majority of Minnesota's domestic terminating markets $[34,35]$.

The medical commodity model utilized in this study provides a different perspective from standard air cargo volume distribution. Table 1 illustrates the discrepancy between volume and value trades. For instance, while MSP to Memphis (MEM) represent a high-volume connection, medical shipments from MSP to Chicago (ORD) are roughly 43 percent more valuable. MSP to Bentonville, Arkansas (XNA) (not pictured in Table 1), home to the Walmart headquarters, exerts the largest discrepancy between volume and value where nearly one-hundredth of a ton translates to a $\$ 13$ million medical value. However, this ratio represents an outlier. Ignoring these outliers, on average, one ton of all commodities originating in Minnesota airports contained \$4 million worth of medical commodities. One ton terminating in Minnesota, on average, 
contained $\$ 134,000$ worth of medical commodities. The findings suggest a complex relationship between import and export medical value chains, which requires future study.

\begin{tabular}{|cccc|}
\hline \multicolumn{2}{|c|}{ Minnesota Origin } & & \\
\hline Destination & $\begin{array}{l}\text { Total } \\
\text { Cargo } \\
\text { Volume } \\
\text { (Tons) }\end{array}$ & $\begin{array}{c}\text { Medical } \\
\text { Value } \\
\text { (Mil.SUS) }\end{array}$ & $\begin{array}{c}\text { Value-per- } \\
\text { ton } \\
\text { (thousand } \\
\text { SUS/ton) }\end{array}$ \\
\hline ORD & 1,374 & 911.03 & 663.05 \\
MEM & 36,350 & 637.86 & 17.55 \\
TPA & 548 & 460.10 & 839.60 \\
RFD & 3,772 & 430.92 & 114.24 \\
MKE & 1,391 & 414.89 & 298.27 \\
\hline Minnesota Destination & & \\
\hline Origin & & & 32.58 \\
MEM & 37,981 & $1,237.42$ & 280.10 \\
ORD & 1,196 & 335.00 & 10.04 \\
SDF & 24,661 & 247.67 & 35.60 \\
MEM & 5,731 & 204.05 & 33.11 \\
PHL & 3,786 & 125.35 & \\
\hline
\end{tabular}

Table 1. Minnesota Airport Top Five Shipment Connections in Volumes and Medical Values,

\section{Discussion}

The medical device industry in Minnesota has established itself not only nationally but globally. With world-renowned health care providers and facilities located in Minnesota, the medical device industry has been able to flourish over the years and with a high reputation and recognition in the advancement in the medical field to improve health care and people's well-being. The success of the industry also benefits other industries. However, while most medical device companies are located in the seven-county metro region, many businesses in the related industry clusters are dispersed throughout the state of Minnesota. As such, there is a continuing if not growing need for a highly efficient and reliable transportation system to support the production and distribution of medical device products. The following are items that have arisen from the findings of this study; addressing them would aid in advancing the understanding and further development of the state's medical device industry and supply chain.

\subsection{Better Data to Guide MSP Medical Trade}

This study has documented that MSP airport plays a critical and essential role in the current and future growth of the medical device industry. Yet, when it comes to air transportation, there is a lack of detailed information on air cargo. There is an abundance of data made available to the public when it comes to passenger travel patterns on flights. To the contrary, there is very little available data on what is underneath the passenger flight in the "belly" of the plane. These passenger planes have the potential to transport more than just people as cargo spaces can be better utilized through shared information. A conversation can be initiated by regional transportation agencies to obtain better air cargo information to consider expanding air cargo routes.

In 2017, a partnership was formed between Greater MSP and the Metropolitan Airports Commission (MAC) in order to add new direct routes out from MSP for passengers [36]. A similar effort could be replicated for air cargo to be better resourceful and efficient. In order for conversations to occur, a proper environment needs to be created for businesses to share information in a way that can be beneficial and non-threatening. The idea of air cargo data sharing must be presented in a manner that everyone involved will be able to benefit from being a participant. The ideal outcome of such conversations with key actors in the air cargo industry is a better grasp of some of the type of goods that get transported on air cargos and their values.

By understanding the value flow of air cargo goods, that information can improve freight mobility and also serve as an example on the effectiveness of a well-coordinated intermodal transportation system to maximize Minnesota's medical device economy and to expand the state's role as a global player in the medical device industry. As a recent example, preliminary discussions are underway to evaluate a partnership between Minnesota (MSP) and a major European Airport to provide a reliable and state of the art medical device import/export services between the US and Europe. The findings of this study have been a part of this nascent discussion, but current data limitations (discussed next) hampers detailed analysis.

\subsection{Model Limitations}

Data limitations affected the model developed in this study. First, this study only analyzes shipments that go to, from, and through other domestic airports. The healthcare economy represents a global supply chain with goods manufactured anywhere from Ireland to Puerto Rico. 
These goods are imported to meet local hospital demands. MSP trades roughly 30,000 tons of goods to and from non-U.S. airports - roughly 12 percent of the total volume share. However, both the domestic nature of FAF4 and limitations within BTS T100 - the dataset does not differentiate between terminal and gateway (i.e., indirect) connections - prevented this model from identifying international trade locations and therefore omitted the 12 percent direct international flights.

Thus better, publicly available cargo and commodity data can expand the findings estimated in this spatial airfreight model and make it more useful for medical device supply chain stakeholders.

\subsection{Research Directions}

This study presents a first attempt to evaluate the spatial distribution of Minnesota's medical device industry cluster and the air network that facilitates the industry's economic competitiveness, using widely available and open datasets. By analyzing value flows of medical goods, rather than just volume, the full shape of Minnesota's medical economy takes form. However, future studies would do well to look at both

\section{References}

[1] Harvard University, "U.S. Cluster Mapping: Mapping a Nation of Regional Clusters." U.S. Cluster, 2020. Retrieved from: http://clustermapping.us/.

[2] L. Munnich, and M. Iacono, "Transportation Planning to Support Economic Development: An Exploratory Study of Competitive Industry Clusters and Transportation in Minnesota”. Research Project Final Report 2015-02, Minnesota Department of Transportation, St. Paul, 2015.

[3] M. Porter, "The Competitive Advantage of Nations," Harvard Business Review, Vol. 68, No. 2, pp. 73-93,1990.

[4] M. Porter," Clusters and the New Economics of Competition," Harvard Business Review, Vol. 76. No. 6, pp. 77-90, 1998.

[5] M. Porter, The Minnesota Medical Devices Cluster. Research for Harvard Business School, 2011. Retrieved from:

http://citeseerx.ist.psu.edu/viewdoc/download?doi=10.1. 1.567.6920\&rep $=$ rep1\&type $=$ pdf. Accessed November $5,2019$. volume and value flows together when making informed freight decisions [37, 38]. Moreover, this study focuses solely on the air transport element of medical device supply. As demonstrated by the spatial distribution of the medical device (and linked) companies, there is a need to examine the surface transportation element of the supply chain. For this reason, the next phase of this research project is focused more directly on the surface transportation connections between specific medical device industry locales and surface and air transportation options. To do so also requires a closer examination of medical device business "hot-spots" in Minnesota and comparative access to MSP. Finally, this study referenced but did not closely examine the range of data that is needed to inform transportation investments. Such considerations will also be examined in follow-up research.

\subsection{StoryMap on Research Findings.}

Finally, reporting results from spatial analysis via a research paper does not permit the reader to experience the interactive and visual dimensions of spatial analysis. Consequently, the authors have created an online "StoryMap" of the research [39].

[6] M. Delgado, M. Porter, and S. Stern. "Defining clusters of related industries," Journal of Economic Geography, Vol 16, No. 1, pp. 1-38, 2015.

[7] M. Waits, "The added value of the industry cluster approach to economic analysis, strategy development, and service delivery," Economic Development Quarterly Vol. 14, No. 1, pp. 35-50, 2000.

[8] C. Ketels, and O. Memedovic. "From Clusters to Cluster-based Economic Development." International Journal of Technological Learning, Innovation and Development, Vol. 1, No. 3, pp. 375-392, 2008.

[9] J. Bröcker, D. Dohse, V. Soltwedel, and Rüdiger (Eds.), "Innovation Clusters and Interregional Competition", New York: Springer Press, 2003.

[10] L. Munnich, and G. Schrock. Rural knowledge clusters: The challenge of rural economic prosperity. "The American Midwest: Managing Change in Rural Transition", New York: Taylor and Francis, pp. 159176, 2016.

[11] M. Delgado, M. Porter, and S. Stern. Defining clusters of related industries. Journal of Economic Geography, Vol. 16, No. 1, pp. 1-38, 2015. 
[12] J. Kasarda and G. Lindsay. "Aerotropolis: The Way We'll Live Next," New York: Farrar, Straus and Giroux, 2011.

[13] M. Maynard, D. Clawson, M. Cocanougher, D. Walter, R. Brimble, M. Webber, R. Janisse, K. Freidheim, and R. Miller, "ACRP Report 143: Guidebook for Air Cargo Facility Planning and Development," Washington DC: Transportation Research Board, 2015.

[14] R. Mayer. Airport Classification based on Cargo Characteristics, Journal of Transport Geography, Vol. 54, pp. 53-65, 2016.

[15] M. Sales, "Air Cargo Management: Air Freight and the Global Supply Chain,”New York: Routledge, 2nd ed., 2016.

[16] Boeing Corporation. World Air Cargo Forecast, 2019, Retrieved From: http://www.boeing.com/commercial/market/cargoforecast.

[17] F. Kupfer, H. Meersman, E. Onghena, and E. Van de Voorde. The Underlying Drivers and Future Development of Air Cargo. Journal of Air Transport Management, Vol. 61, No. C, pp. 6-14, 2017.

[18] K. Alkaabi and K. Debbage. The Geography of Air Freight: Connections to U.S, Metropolitan Economies. Journal of Transport Geography, Vol. 19, pp. 15171529, 2015.

[19] B. Feng, L. Yanzhi, and M. Shen. Air Cargo Operations: Literature Review and Comparison with Practices, Transportation Research Part C, Vol. 56, 2015: 263-280.

[20] P. Lakew, Airport Traffic and Metropolitan Economies: Determinants of Passenger and Cargo Traffic, Transportation Research Record, No. 2471, pp. 58-72, 2015.

[21] P. Lakew and A. Tok, Determinants of Air Cargo Traffic in California, Transportation Research Part A, Vol. 80, pp. 134-150, 2015.

[22] K. Button and J. Yuan, Airfreight Transport and Economic Development: An Examination of Causality, Urban Studies, Vol. 50, No 2, pp. 329-340, 2013.

[23] T. Niine, E. Kolbre, and A. Miina, Enablers and Constraints of Peripheral Air Cargo: A Case Study of Estonia, Journal of Air Transport Management, Vol. 61, pp. 106-114, 2017.

[24] Minnesota Department of Employment and Economic, Development Overview of Medical Device Industry, 2020.

[25] Harvard University, U.S. Cluster Mapping: Mapping a Nation of Regional Clusters." U.S. Cluster, 2020: Retrieved from http://clustermapping.us/.
[26] Minnesota Department of Transportation, "Corridors of Commerce Program Report - Minnesota", 2020. Retrieved from: https://www.dot.state.mn.us/corridorsofcommerce/about .html

[27] Twin Cities Pioneer Press, Minnesota MN company's medical devices in demand for coronavirus tests, but supply chain a problem, April 15, 2020.

[28] ReferenceUSA, 2019. Retrieved from: http://resource.referenceusa.com/.

[29] Harvard University, "U.S. Cluster Mapping: Mapping a Nation of Regional Clusters." U.S. Cluster, 2020. Retrieved from: http://clustermapping.us/.

[30] K. Alkaabi and K. Debbage, The Geography of Air Freight: Connections to U.S. Metropolitan Economies. Journal of Transport Geography, Vol 19, pp. 1517-1529 2011.

[31] A. Kim, A and Q. Fu, Supply-and-demand Models for Exploring Relationships between Smaller Airports and Neighboring Hub Airports in the U.S. Journal of Air Transport Management, Vol. 52, pp. 67-79, 2016.

[32] SITA Logistics. MSP Air Cargo Study. 2001. Retrieved from: http://www.dot.state.mn.us/aero/planning/documents/pu blications/mspaircargostudy.pdf

[33] A. Micco, and T. Serebrisky, Competition regimes and air transport costs: The effects of open skies agreements, Journal of International Economics, Vol. 70. No. 11, pp. 25-51, 2006.

[34] Bureau of Transportation Statistics, Airline Carrier Statistics (Form 41 Traffic): T-100 Segment, 2019.

[35] Federal Highway Administration. Freight Analysis Framework 4, 2019. Retrieved from: https://ops.fhwa.dot.gov/ freight/.

[36] Greater MSP, Regional Air Service Partnership, 2020. Retrieved from: https://www.greatermsp.org.

[37] K. Alkaabi, and K. Debbage, The Geography of Air Freight: Connections to U.S. Metropolitan Economies, Journal of Transport Geography, Vol. 19, pp. 15171529, 2011.

[38] University of Minnesota, Medical Device Study StoryMap, 2020. Retrieved from: https://tinyurl.com/mnmedicaldevices 